\title{
Fregean Sense and Anti-Individualism
}

\section{Daniel Whiting}

The definitive version of this article is published in Philosophical Books 48.3 July 2007 pp. 233-240 by Blackwell Publishing, and is available at www.blackwell-synergy.com.

\section{Introduction}

In Anti-Individualism and Knowledge, ${ }^{1}$ Jessica Brown aims to show that 'anti-individualism lacks the radical epistemic consequences commonly suggested' (p. xii). According to antiindividualism, semantic and mental content are partly determined by one's physical and/or social environment. The epistemic consequences concern, specifically, subjects' ability to know a priori the contents of their minds.

Brown's book is undoubtedly important and should set the agenda for future discussion. It not only offers a judicious survey of the prominent views in the vast (seemingly unmanageable) literature on the epistemological implications of anti-individualism; it makes a significant contribution to the debate. On each issue, Brown advances - and defends against rivals - a novel position deserving serious consideration. In what follows, I shall focus on her claim that antiindividualism is incompatible with Fregeanism. But first I shall briefly outline the other problems Brown investigates and her suggested solutions (I shall not mention her many criticisms of competing views). 
Roughly half the book (Chs. 2-4) is devoted to the 'achievement problem'. It seems a platitude that a subject has privileged access to the contents of her mind. But anti-individualism appears to be incompatible with this platitude. If mental content is partially determined by the environment, surely a subject needs empirical knowledge about that environment in order to know what she thinks.

Brown traces the alleged problem to the view that knowledge requires discriminative abilities. The reason anti-individualism appears to undermine privileged access is that a subject is unable 'to distinguish a priori between the thought contents she actually has and the thought contents she would have in various counterfactual situations' in which her environment differs (pp. 37-8). Brown's response is to challenge the assumption that the counterfactual situations that would undermine a subject's discriminatory abilities are normally relevant. So, that a subject cannot distinguish a priori the actual situation in which she thinks that $p$ from alternative situations in which she thinks a different thought due to an environmental difference does not affect whether she knows that she thinks that $p$, since those alternatives are not relevant.

Next, Brown investigates whether anti-individualism undermines a certain conception of ourselves as rational agents (Ch. 5). According to that conception, we are 'able and disposed to conform [our] thoughts to the laws of logic a priori' (p. 192). If anti-individualism is true, subjects are unable to grasp a priori of any two thoughts whether they are similar or different in content, and are therefore easily mistaken about the logical relations between them. Since this will inevitably lead to subjects making simple errors in reasoning, they do not fit the above conception of rationality. Brown's swift response is to claim that there are independent grounds 
to reject such a conception of ourselves. Moreover, anti-individualism provides a partial exculpation of subjects' rational shortcomings. If thoughts are externally individuated, subjects cannot be blamed for simple mistakes concerning their logical relations.

Finally, Brown discusses the 'consequence problem' (Chs. 7-8). Assuming anti-individualism is true and compatible with privileged access, it appears that a subject can gain substantive knowledge about her environment from a priori knowledge that she has a certain thought plus a priori knowledge that having that thought entails some fact about her environment. For example:

1. I think that water is wet.

2. If I think that water is wet, then there is water in my environment.

C. Therefore, there is water in my environment.

This seems a reductio ad absurdum of anti-individualism.

Brown rejects the assumption behind (2), namely that anti-individualism allows one to know a priori that having a certain thought entails the environment is a certain way. Anti-individualism, she claims, establishes only a counterfactual dependency of thought on environmental conditions. It is silent as to what relations actually hold between one's thoughts and the environment.

In the midst of these discussions, one stands out. Brown's investigation of whether one can be Fregean and anti-individualist is marked as the only one not conciliatory in nature (Ch. 6). The main thrust of the book is to show that anti-individualism does not, despite appearances, have radical consequences. But on the issue of Fregeanism Brown is decidedly less accommodating. 
She argues - contrary to the views of Campbell, Evans, McDowell and Peacocke ${ }^{2}$ - that Fregeanism is incompatible with anti-individualism.

I think Brown's arguments for this claim are inconclusive. I shall suggest various options, which Brown either overlooks or leaves under-discussed, which the Fregean anti-individualist might endorse in order to defend her position. ${ }^{3}$

\section{Brown's Incompatibility Argument}

Fregeans hold that mental or semantic content is not exhausted by reference; in addition, there is sense. Sense is, roughly, a way of taking or conceiving of the reference. Thus, sense is more finegrained than reference. Two expressions can share their reference but differ in sense (for example, 'featherless biped' and 'human').

As Brown presents them, Fregeans think the notion of sense is required 'to provide an adequate psychological understanding of [rational] agents' (p. 193). Specifically, it is needed to explain the following:

that agents take some identity judgements to be informative;

agents' ability to make simple, valid inferences;

the beliefs agents' behaviour warrants ascribing;

that agents do not have obviously contradictory beliefs.

So, for example, a non-Fregean holds that 'A featherless biped studies philosophy' and 'A human studies philosophy' express the same belief. But, the Fregean argues, one could 
coherently take opposing psychological attitudes toward the propositions expressed by these sentences. Our individuation of content must, therefore, be more fine-grained. Thoughts or utterances whose constituents have the same reference may nonetheless differ in sense.

Importantly, Brown claims, Fregeanism rests on two assumptions (p. 200):

(1) that sameness of content is transparent;

(2) a certain conception of rationality.

That this is so is clear from the above. It is because the Fregean wants to secure a certain conception of rationality (according to which agents do not, for example, hold obviously contradictory beliefs) that the notion of sense is invoked.

For sameness of content to be transparent is for an agent to be able to realize a priori, for any two thoughts she entertains with the same content, that they have the same content (p. 195). Brown accepts that Fregean anti-individualism is compatible with (1), due to its fine-grained individuation of content. Her strategy is, instead, to claim that the Fregean anti-individualist's commitment to (2) is ill-motivated.

Crucial is Brown's allegation that Fregean anti-individualism is incompatible with transparency of difference of content. For difference of content to be transparent is for an agent to be able to realize a priori, of any two thoughts with different content that she has, that they have different content. Brown introduces a scenario designed to demonstrate this incompatibility. ${ }^{4}$ 
Clara is acquainted with the terms 'einsteinium' and 'fermium'. She knows that each refers to an element but not that they refer to distinct elements. Further, she has 'such causal and/or deferential relations that an anti-individualist would accept that she has beliefs involving those concepts' (p. 218). Clara believes that einsteinium is an element, and she believes that fermium is an element. But she wonders if her two beliefs have the same content. Given that they refer to different elements, they in fact have different content, yet Clara lacks the empirical knowledge to know this. Thus, difference of content is not transparent.

Importantly, the Fregean notion of sense cannot be used to show that there is no difference of content here after all; it can only introduce more fine-grained differences.

Having (supposedly) established that it is incompatible with transparency of difference of content, Brown raises her objection to Fregean anti-individualism. She points out that as a Fregean, one must endorse transparency of sameness of content, and allow that rational subjects typically grasp a priori simple instances of inferential validity. But as an anti-individualist, one must reject transparency of difference of content, and allow that rational subjects cannot always recognize a priori simple instances of inferential invalidity. And this seems, as Brown nicely puts it, 'strangely asymmetric' (p. 226).

This shows, Brown argues, that the Fregean assumption (2) is ill-motivated. What can support that conception if one accepts difference of content is not transparent, and subjects are disposed to make invalid inferences? The conception of a rational agent that the Fregean anti-individualist 
subscribes to seems lopsided. And if that lopsided conception of rationality is not compelling, then neither is Fregean anti-individualism.

Brown is surely right that this asymmetric conception of rationality would leave Fregeanism lacking convincing motivation. What this shows, then, is that the Fregean anti-individualist must demonstrate that sense can be transparently different.

In what remains of this paper, I shall introduce various options that the Fregean might draw upon to show that Fregeanism is indeed compatible with transparency of difference of content, and thereby anti-individualism. All are options that Brown either fails to consider, or does not convincingly reject. Some may ultimately be untenable, but the burden of proof lies with Brown.

\section{Damage Limitation}

One tactic would be to question the significance of a scenario such as Clara's. Even granting its possibility, it is far from clear that it should trouble the Fregean. What the scenario shows is that it is possible for difference of content to be opaque; it does not show that it necessarily is, as Brown seems to suggest. Surely only the latter would be a threat to Fregeanism.

Likewise, that difference of content is opaque in that particular case does not show that difference of content is generally opaque. The Fregean could grant that instances such as Clara's might occur, and nonetheless maintain that difference of content is normally transparent, or at least that nothing has been done to show that this is not so. It is not obvious that Fregeanism requires a stronger claim to remain well-motivated. 
True, as Brown introduces it, transparency of difference of content requires that for any two thoughts, with different content, subjects be able to realize a priori that they have different content. But the Fregean could object to such a strong formulation, and suggest that the following is both available and adequate. For difference of content to be transparent is for it to be the case that, for two thoughts with different content, rational subjects can normally, typically or usually realize a priori that they have different contents. ${ }^{5}$

If attitudes such as Clara's were to become more widespread, maybe the Fregean individuation of thought would cease to have application. But Brown has certainly not shown that the Fregean needs to take this possibility seriously. Conceptual schemes often rest on contingencies. Since the Clara case does not show that content is not normally, for the most part, transparently different, the Fregean notion of sense may yet be compatible with anti-individualism.

\section{A No-Concept Interpretation}

A Fregean could deny that Clara has the relevant concepts at all. Of course, Clara may be able to token expressions typically or conventionally used to express the belief (say) that einsteinium is an element. But that does not show she is actually capable of having that belief, or (to put it another way) of entertaining the thought required to understand such utterances.

This view is supported by the following observations. Not only is Clara ignorant of the chemical compositions of the respective elements (p. 215), but she could not provide an explanation of the concepts were she called to do so, has an incomplete grasp of the inferential proprieties 
governing them, is unaware of what warrants their application, does not know what counts as an incorrect employment of those concepts, and so on. Arguably, such norms are (at least partly) constitutive of the relevant concepts. Thus, there are strong grounds for claiming that, since she is not party to those norms, she does not genuinely possess the concepts. The upshot of this interpretation of the scenario is that, if Clara lacks the relevant concepts, she cannot entertain beliefs about the respective elements, and so (since there is no content to distinguish) there is no counterexample to transparency of difference of content.

It is true, as Brown says, that many anti-individualists would claim that —in virtue of her deference and causal relations - Clara possesses the concepts (p. 218). But this is immaterial. What matters surely is which view is correct, not most popular. Further, were a Fregean antiindividualist to appreciate the force of Brown's discussion, she might be more inclined to assess the availability and cogency of this claim. ${ }^{6}$

\section{The Instability Argument}

A rather different move to consider that is potentially available to the Fregean is to adopt a more offensive rather than defensive position. One might highlight an instability or tension in Brown's appeal to a scenario such as Clara's. That instability can be summarized as follows. To get the intended result, namely that Fregeanism is ill-motivated, Brown requires both that subjects do not make simple invalid inferences and that they do. The former is needed to demonstrate that difference of content is opaque, the latter to undermine the Fregean conception of rationality. Clearly, the two requirements are incompatible. I shall expand on this charge in what follows. 
As Brown admits, it is a crucial feature of the scenario that Clara not treat the two constituents of content, corresponding to the expressions 'einsteinium' and 'fermium', as identical or intersubstitutable. So, in particular, Clara must not employ them in simple invalid inferences such as:

1. There is einsteinium

C. Therefore, there is fermium

Were she to do so, there would be no barrier to denying either that she possess the relevant concepts at all — since her misunderstanding is too gross — or, more significantly, claiming that she possesses only a single concept ('feinsteinium'), one which is more coarse-grained than those typically associated with the two terms. Clara's essential diffidence keeps the role of these concepts in her cognitive life suitably distinct. As Brown herself insists:

[Clara's] uncertainty about whether the elements are identical prevents her from putting Einsteinium and Fermium beliefs together in inference and thus helps preserve their distinct causal histories [and so their distinct identities]. (p. 219)

So, although the Clara scenario demonstrates that difference of content is sometimes opaque, it only does so on the condition that, among other things, a subject is not disposed to make simple invalid inferences involving the relevant concepts.

Recall now how the denial of transparency of difference of content is supposed to bear on Fregeanism. Its merely being the case that difference of content is opaque is clearly insufficient to undermine the Fregean conception of rationality. Rather, the concern is that, if content is opaque, subjects will be disposed to make simple invalid inferences. It is this that threatens the Fregean anti-individualist's efforts to secure her particular conception of rational subjects. So, commitment to that conception of rationality is undermined on the condition that, among other 
things, subjects such as Clara (for whom difference of content is opaque) put the relevant different contents together in various, simple invalid inferences.

Here, then, is the instability, which should by now be manifest. Brown requires that Clara both refrain from making simple invalid inferences - in order to show that difference of content is opaque — and not refrain from doing so — in order to undermine the Fregean conception of rationality.

It is not obvious how Brown could resolve this tension. If she were to allow Clara to make inferences involving the concepts, her case against transparency of difference of content would be weaker, insofar as it becomes hard to maintain that there are different contents at all. If she were to disallow Clara from making inferences involving the concepts, transparency of difference of content would be no threat to the Fregean conception of rationality. That is, even if it were the case that difference of content is sometimes opaque, subjects would still not make simple invalid inferences involving such contents. The Fregean conception of rationality would remain well-motivated.

This is not a knockdown argument. Brown may be able to reconstruct the Clara scenario, or provide a different example, which is not unstable in this way. But until she does so, it remains to be shown that the Fregean notion of sense is incompatible with anti-individualism.

\section{Implicit Awareness}


Perhaps Brown is over-intellectualizing what is required for transparency of difference of content. Clara may implicitly, tacitly, or unreflectively realize that her beliefs have different contents (as is shown in the inferences she is prepared to make, in her attitudes towards the beliefs, in the behaviour she exhibits that warrants belief-ascription, and so on). Thus, in this sense, she does indeed (in a sufficiently robust and significant respect) know, or realize a priori, that her beliefs differ in content.

One can concede that at a certain level, that of meta-linguistic or second-order reflection, Clara might not claim that they are different beliefs, but why should that be the criterion for whether difference of content is transparent? The onus is on Brown to show that it is. Transparency need only require that a subject's first-order cognitive activity displays an implicit awareness that the thoughts differ in content, and is sufficiently sensitive to that difference.

Brown might offer the following rejoinder to this suggestion. Were Clara genuinely to find herself unsure as to whether her two beliefs - that einsteinium is an element and that fermium is an element - differ in content, it would impact her first-order reasoning involving such beliefs. The criterion for transparency of difference of content cannot, then, be confined to lower-order activity.

A further rejoinder would be to investigate just what influence Clara's speculation could have. Either she judges their content to be the same and subsequently treats the concepts of einsteinium and fermium as interchangeable, or she refrains from using contents containing the concepts 
together in inferential reasoning. One could then run the arguments from the previous section to show that neither possibility is a threat to Fregean anti-individualism.

\section{Conclusion}

Brown has yet to show that Fregean theory and anti-individualism are in tension. There are various strategies available for demonstrating that Fregean anti-individualism is compatible with transparency of difference of content, and thereby anti-individualism. While one or more of the suggestions may ultimately prove unsuccessful, the remaining may yet stand fast. ${ }^{7}$

\section{Notes}

1 Jessica Brown, Anti-Individualism and Knowledge (MIT Press, 2004. xiv + 340 pp. \$25.00). All page references will be to this text.

2 See J. Campbell Past, Space, and Self (MIT Press, 1994); G. Evans The Varieties of Reference (Oxford University Press); J. McDowell Meaning, Knowledge, and Reality (Harvard University Press, 1998); and C. Peacocke Sense and Content (Oxford University Press, 1983).

3 Throughout I shall focus on natural kind and social anti-individualism. Singular antiindividualism requires a somewhat different treatment and cannot be adequately discussed here.

${ }^{4}$ From B. Frances, 'Contradictory Belief and Epistemic Closure Principles', Mind and Language 14 (1999), pp. 203-266.

5 A variant would be to accept Brown's definition, and so accept that difference of content is not transparent, but claim that Fregeanism only requires that a subject can typically or usually realize a priori, of any two thoughts with different contents that she has, that they differ in content. 
${ }^{6}$ How amenable this suggestion is to anti-individualism will vary according to which version one endorses, and which 'external' factors one considers determinative of content. In order properly to assess the suggestion, one would need to consider the plethora of different positions separately. Like Brown, though, I shall keep the discussion at a more general level.

${ }^{7}$ I am grateful to the Arts and Humanities Research Council whose funding made it possible to write this paper. Thanks to David Oderberg and Charlie Pelling for helpful feedback on earlier versions. Also, thanks to the reading group at the University of Reading and the audience at the Joint Session of the Aristotelian Society and the Mind Association (2005) for discussion of this material. 